\title{
Implementation of Multi-Agent based Digital Rights Management System for Distance Education (DRMSDE) using JADE
}

\author{
Ajit Kumar Singh ${ }^{1}$, Akash $\mathrm{Nag}^{2}$, Sunil Karforma ${ }^{3}$, Sripati Mukhopadhyay ${ }^{4}$ \\ Department of Computer Science, The University of Burdwan, Burdwan, India ${ }^{1,3}$ \\ Department of Computer Science, MUC Women's College Burdwan, India ${ }^{2}$
}

\begin{abstract}
The main objective of Distance Education (DE) is to spread quality education regardless of time and space. This objective is easily achieved with the help of technology. With the development of World Wide Web and high-speed internet the quality of DE is improved because now Digital Content (DC) can be easily and in no time distributed to many learners of different locations in text, audio and video formats. But, the main obstacle in digital publishing is the protection of Intellectual Property Rights (IPR) of DC. Digital Rights Management (DRM) that manages rights over any digital creation is the only solution to this problem. In this paper, we have made an attempt to implement a Digital Rights Management System for Distance Education known as DRMSDE. We have identified that MultiAgent System (MAS) based technology is very popular for such type of implementations. Keeping that in mind, we have chosen one of the most popular Multi-Agent based tools, namely JAVA Agent Development Framework (JADE), for our system. This paper presents an overview and the system architecture for the proposed implementation.
\end{abstract}

Keywords-Distance Education (DE); Intellectual Property Rights (IPR); Digital Rights Management (DRM); Multi-Agent System (MAS); JADE

\section{INTRODUCTION}

The advancement of Information and Communication Technologies (ICT) touches every aspect of life [1], and knowingly or unknowingly we all are part of this technological revolution. The areas that are affected most are telecommunication, commerce, education, health and the media industry. Education with ICT reaches every corner of the globe within a fraction of a second under the domain of DE. DE is the most demanding and popular education system running in parallel to the traditional education system. The reason behind the popularity of $\mathrm{DE}$ is the flexibility of studying with respect to time and place. The main source of DE is DC that includes assignments and text tutorials along with advanced audio and video tutorials. DC may easily be copied and used by multiple users simultaneously. This advantage of DC sometimes becomes problematic because unauthorized users can also use and even modify DC, which is against the content-creators' IPR. Our main purpose is to protect IPR using the technology available with us, and thereby, preventing misuse of content.

Maintaining the rights of the different users in DE is a big challenge and it affects the quality of DE. DRM is the only solution to this problem. DRM is a combination of hardware and software, collaborating to protect the rights of content creators. There are two generations of DRM [2]; in the first generation DRM, digital contents are locked and the users, who pay, then only use the content. Second Generation DRM includes identification, protection, monitoring, and tracking of all forms of rights, permissions etc.

In this study, we have designed and implemented a Distance Education System (DES) with DRM for protection of IPR for DC. Here we are using both approaches. For text tutorial, we are using second generation DRM and for advanced tutorial we are using first generation DRM. Our system is known as DRMSDE [3]. Here we are using MAS [4, 5] approach for the implementation of our system. An agent based approach is a new paradigm for software implementation. Agents are programs that take some input from systems as well as from some other agents, and perform actions for the system. In MAS at least two or more agents cooperate to achieve system goal. Real world problems can be successfully implemented using MAS. One of the major advantages of agent-based system is that we can easily upgrade the system by introducing a new agent. In case of DE, new experiments are done every time. MAS is good for domains like DE. There are so many tools to implement MAS but among all, JADE [6] is very popular. JADE, is a software framework that is used to build MAS. It is a middleware that includes a run-time environment, library and graphical tools. JADE is in compliance with FIPA specification, it has predefined programmable and extensible agent model that helps to develop MAS. JADE is the most popular agent development tool.

This paper is organized in six sections; Section 2 discusses some literature on agent-based DES. Section 3 describes the proposed DRMSDE system model in which we discuss the different components of our system. Section 4 presents the proposed system architecture, while Section 5 discusses implementation details. Finally, Section 6 concludes our work throwing some light on future applications and scope for improvement.

\section{RELATED WORK}

In the life cycle of DC we need to protect it from unauthorized users by DRM techniques [7]. DRM can be achieved in two ways [8]-using Right Expressions, and 
through Authentication and Authorization. In Right Expressions, permissions and conditions are expressed in machine-readable form using Right Expression Language (REL) and right expressions follow DC throughout its life which is very essential for commercial distribution. In Authentication and Authorization technique, users are first authenticated based on their login credentials (usually a login ID and password). After successful authentication; the system checked whether they are authorized to perform certain actions on DC based on the type of user. The general architecture of a DRM-based educational system is shown in Fig. 1.

In a country $\mathrm{DE}$ is hosted by either public or private sectors. Regardless of who provides education, an effective DRM system is very much essential for fare use. We now list below some existing Education Systems based on DRM that are in use throughout the world:

\section{A. BOKAHRI-IMBLS [9]}

BOKHARI Intelligent Multi-agent based e-Learning System (BOKHARI-IMBLS) is a research model developed in Aligarh Muslim University in 2014 by Prof. Mohammad Ubaidullah Bokhari and his scholar Sadaf Ahmad. This is a web-based interactive E-Learning system designed for the distance learning environment using MAS. The main objective of the system is to incorporate intelligence, accessibility, interactivity, adaptability, collaborative and security into a single system. Its architecture has four levels which are user level that describes human agents, web level describes high interactive websites, system level has Seven interactive Agents (Student Interface Agent (SIA), Tutor Interface Agent (TIA), Collaboration Agent (CA), Intelligent Decision Support Agent (IDSA), Test/Evaluation Agent (TA), Lesson Planning Agent (LPA) and Security Agent (SA)) to achieved system goal and finally the storage level describes profile and content database. BOKHARI-IMBLS takes care of security issues of E-learning systems.

\section{B. EDU-DRM}

The Turkish government is taking an initiative to promote digital education in schools under a project called "Movement of Enhancing Opportunities and Improving Technology" known as FATIH in 2011 [1]. Under this project thousands of schools and classes are equipped with modern ICT tools. DC are created by many authors. FATIH project requires a DRM System to monitor and distribution of DC. EDU-DRM is a new DRM system for FATIH. In EDU-DRM, bitwise logic based encoding approach is used to implement REL that require minimal space in the database.

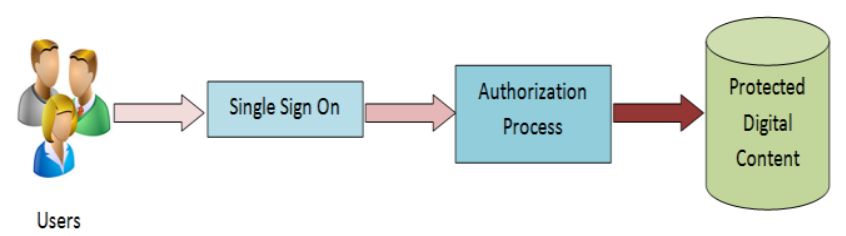

Fig. 1. General Architecture of DRM in Education.

\section{Jorum}

Though the dictionary meaning of 'jorum' is a large vessel, here it represents a large digital repository. The Joint Information Systems Committee (JISC) is designed as an eLearning repository for staff in UK Universities and colleges to share, reuse and re-purpose e-learning and teaching resources (Jorum) in 2005. Teaching and supporting staff create the repository and use it for preparing a lesson plan for students. Parts of this repository use DRM for security. Some materials of JORUM are free but some are protected by DRM [8]. JORUM uses two licenses, one allows re-purposing of content and the other does not.

\section{FDRM}

Federated Digital Rights Management (FDRM) [10] is a DRM solution in the field of education and research. The purposes of the FDRM project are to support local and interinstitutional sharing of resources in a discretionary secure and private manner and protecting the rights of user and creator. In FDRM rights records are written in XML. The FDRM has Resource Attribute Authority, Object Attribute Resolver, License Service and Resource Manager Components for secure content delivery using PGP or JSP and an Apache module or in JAVA. In the next section we will now describe DRMSDE system model.

\section{E. EduSource}

eduSource is a project by Canadian public-private partnership for the network of learning objects in French and English language and accessible to all Canadians for DRM implementation in eduSource. New Brunwick Distance Education Network (NBDEN) one of the partners of eduSource plays a lead role [11]. eduSource is designed to support multiple DRM models, including free access, cooperative sharing, fee-based, subscription-based, etc. [8]. In eduSource Open Digital Rights Language (ODRL) and XML are used in implementing DRM.

\section{F. COLIS}

The Collaborative Online Learning and Information System (COLIS) is a distributed online learning project incorporated with DRM and funded by the Australian Federal Government Department of Education Science and Training (DEST) in the year 2002 [8]. The learner enters into the system with login ID and password and session length. After successful login, the learners see their names on the title and select course under courses. The learner chooses DC for access but before accessing the content an "End User License Agreement and Copyright notice" is displayed that show some copyright related terms and conditions. If the learner has the access right then he or she uses it. Otherwise, Digital Right Error will occur [12].

\section{DRMSDE SYSTEM MODEL}

The DRMSDE is a prototype model for securing DE in which the rights of different users are properly maintained. In our system, the major components are users, DC and roles/rights of users on Digital material. In this section we explain each component in details as follows: 


\section{A. Users}

Presently in DRMSDE we allow following three types of users to use the system which are:

1) Administrative manager: An Administrative manager is a group of experts who control the entire system.

2) Learner: A group of knowledge-seekers/students, i.e. consumers of our system.

3) Content creator: Content Creators are a group of teachers who create content, i.e. they are producers of DC on different topic for different subject in a particular course and inform learners about their creations periodically.

\section{B. Tutorial}

The core component of DE is its tutorial. In our proposed system we broadly classify tutorials into two types: one is DE tutorial and another is advanced tutorial. The DE tutorials are provided by the DE authority to users that has valid DRM code. Advanced tutorials are also maintained by the DE authority but for accessing advanced tutorials, learners have to purchase a license key from DE authority. After getting the license key learners are able to use both tutorials related to his/her course because a DRM code is given to all registered users. The concept of DE tutorial and Advanced Tutorial are similar to textbooks and reference books for a particular subject.

\section{Roles of Users}

Roles of a user are determined on the basis of what the user may do. Roles of our users are:

1) Administrative manager: Administrative Managers are the super user of DE System. They assign Access rights to other users of the system and fully access the entire DC and other databases.

2) Learner: The Learners can view; download copy and print DC related to their course for a specified period of time but cannot erase and modify DC.

3) Course creator: Course creators are group of teachers responsible for creating, managing and modifying tutorials.

In the next section we will describe DRMSDE system Architecture.

\section{DRMSDE SYSTEM ARCHITECTURE}

Proper rights management is essential for the implementation of DE successfully. The main objective of our proposed Multi-Agent based DRMSDE system is to provide a secure environment in which authorized Learners can freely access their own DC according to their rights, needs and their own convenience. Our proposed system is shown in Fig. 2. The agents of our system that perform various operations are Learner Agent, Content Creator Agent, Administrative Manager Agent and Authentication Agent.

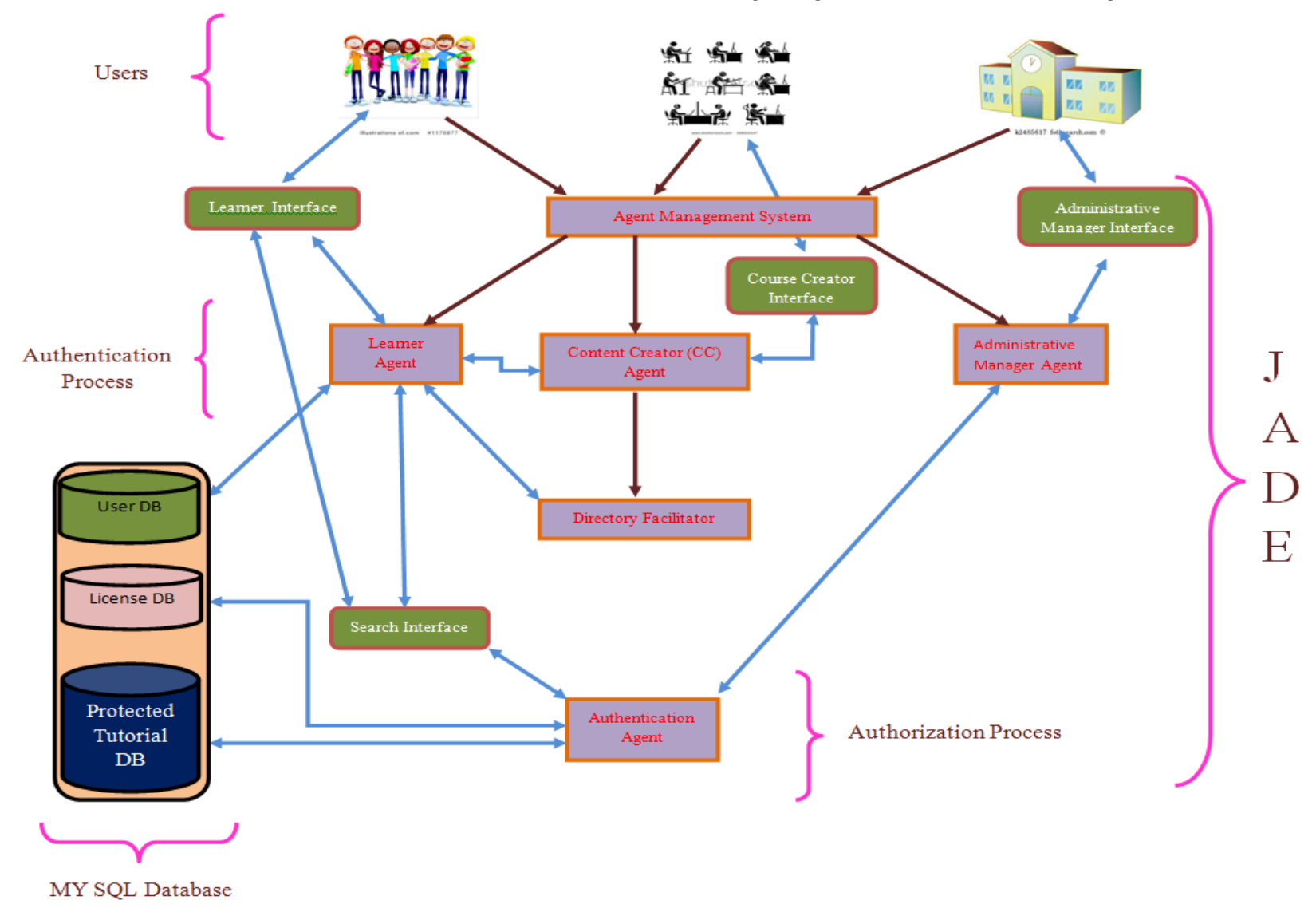

Fig. 2. DRMSDE System Architecture. 
Each individual agent is now described below:

1) Learner Agent: It Receives UserId and Password from Learner interface and checks the authenticity of a user by communicating with the user database. The Learner Agent communicates with a Directory Service Agent for available Content Creator Agents and communicates with appropriate Agents for the tutorial requested by the Learner.

2) Content Creator (CC) Agent: CC Agent receives UserId and Password from CC Interface and matches these with the UserId and Password of Content Creator stored in the user database and display an appropriate message to CC. CC agents register to Directory Service Agent (DSA) so that Learner agent can find them when required. CC Agents create tutorials of a different type for different courses and inform the learners about the tutorial for access through DSA. Tutorials are available in two forms one is paid and other is free.

3) Administrative Manager Agent (AMA): Like Learner and Content Creator Agent, Administrative Manager Agent also receives UserId and Password from its Interface and checks the authenticity of administrative Manager through User Database. AMA registers Learners and Content Creators. It also initiates Authorization Agent when Learner wants to access tutorial.

4) Authorization Agent: This agent is responsible for authorizing the learners when he or she tries to access the tutorial. Our system provides two modes of tutorial access one is free and another paid. To access the free tutorial, learners have to enter DRM code, which is a code given to the Learner by our system at the starting of each semester. DRM code is course and semester specific. Authorization agent matched DRM Code with free tutorial and after proper verification from database Agent allow learner for access. In case of paid tutorial Learners have to follow License procedure with AMA and with License Key Authorization Agent authorizes the Learner for the paid tutorial. Besides the above agents, when the main container is launched, two agents, which are Agent Management System (AMS) and Directory Facilitator (DF) are automatically started by JADE. All the user defined agents are initiated by AMS [13]

5) Agent Management System (AMS): Basically AMS supervises the entire JADE platform. It is the contact point for all agents that need to interact in order to communicate with each other. All agents contact each other through AMS.

6) Directory Facilitator $(D F)$ : $\mathrm{DF}$ is the agent that implements yellow page service used by any agent wishing to register its service for other available services. In our system agents are registered with DF and Learner request the DF for a list of active CC agents. The JADE DF accepts subscriptions from agents that wish to be notified whenever a service registration is made that match some specified criteria. In the next section we will now discuss DRMSDE system Implementation.

\section{DRMSDE SYSTEM IMPLEMENTATION}

MAS can be built with any programming language [14], but Object Oriented Programming Language is better because the concept of objects and agents is similar to some extent. Besides programming language, the software platforms and frameworks are key to implement MAS. The platform provides a middleware to support execution and other essential operations. For our System Implementation, we are using popular Windows 8.0 operating system. JAVA, a powerful Object Oriented Programming Language for system development, for the database we are using MYSQL and for agent interaction JADE 3.4 is used. We choose JADE [15] to build our system because of the following reasons:

- JADE is one of the best modern agent environments.

- JADE is capable to work on distributed and heterogeneous platform.

- JADE is open source software compliant with FIPA specification.

- JADE architecture matches with our system requirement.

- JADE simplifies development of agents and their communication.

\section{A. System Execution [16, 17]}

To see the working of agents in our DRMSDE we need to execute the system. When we run our Agent-Based DRMSDE system then JADE environment demanded user id and password for authentication of administrative manager agent. This creates administrative manager agent and start Administrative manager GUI (see Fig. 3) and JADE environment (see Fig. 4) are displayed.

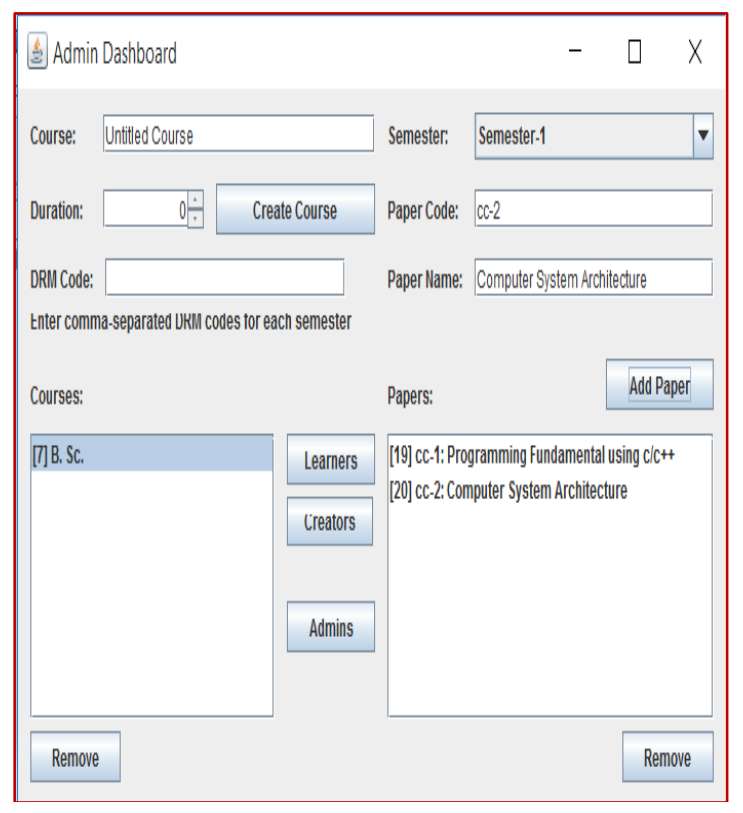

Fig. 3. Administrative Manager GUI. 


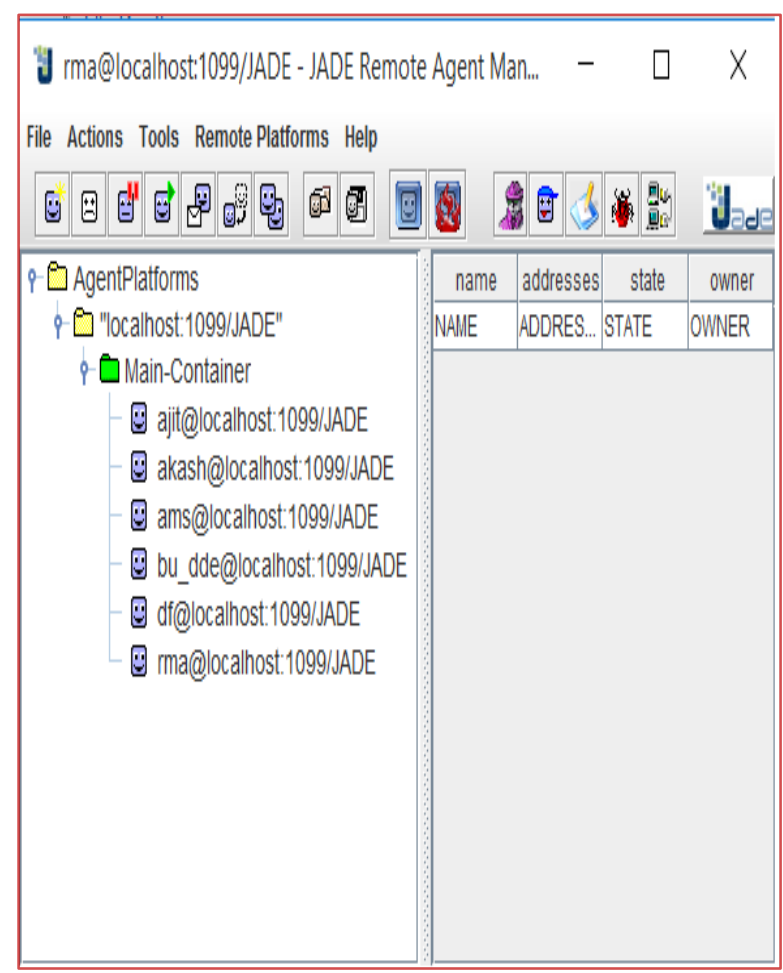

Fig. 4. JADE Environment.

From the administrative manager GUI, admin can create different courses, enroll Learners (see Fig. 5) to various courses and register content creators (see Fig. 6 ) into our system who provide audio, video and text tutorial in two modes free and paid.

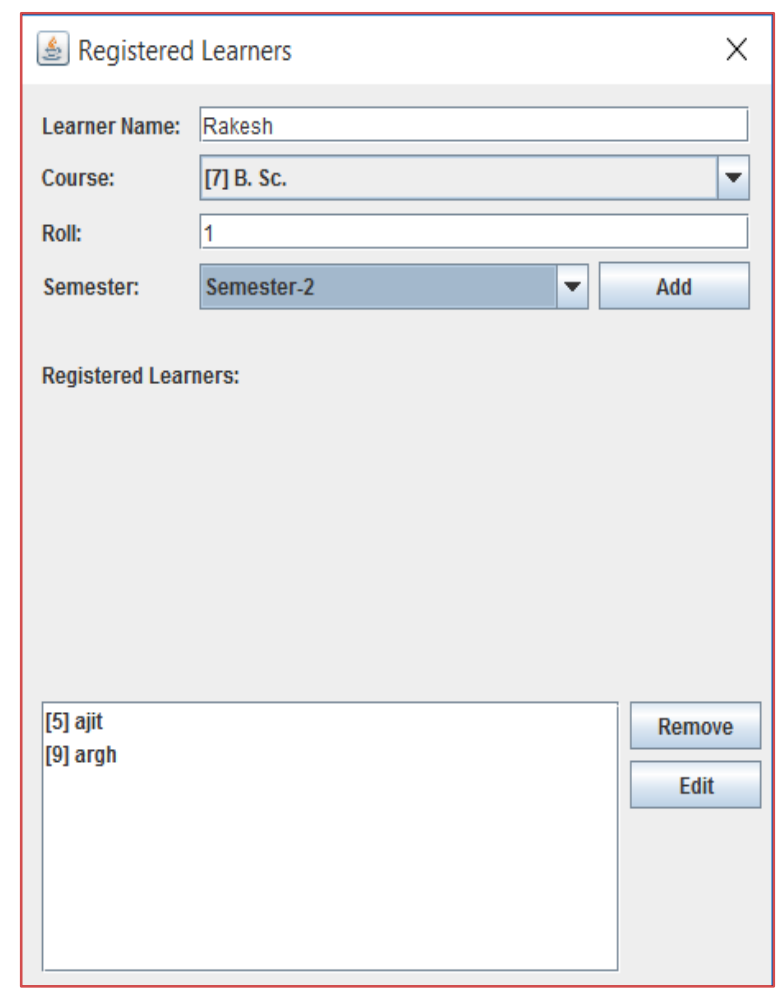

Fig. 5. Learner Enrollment.

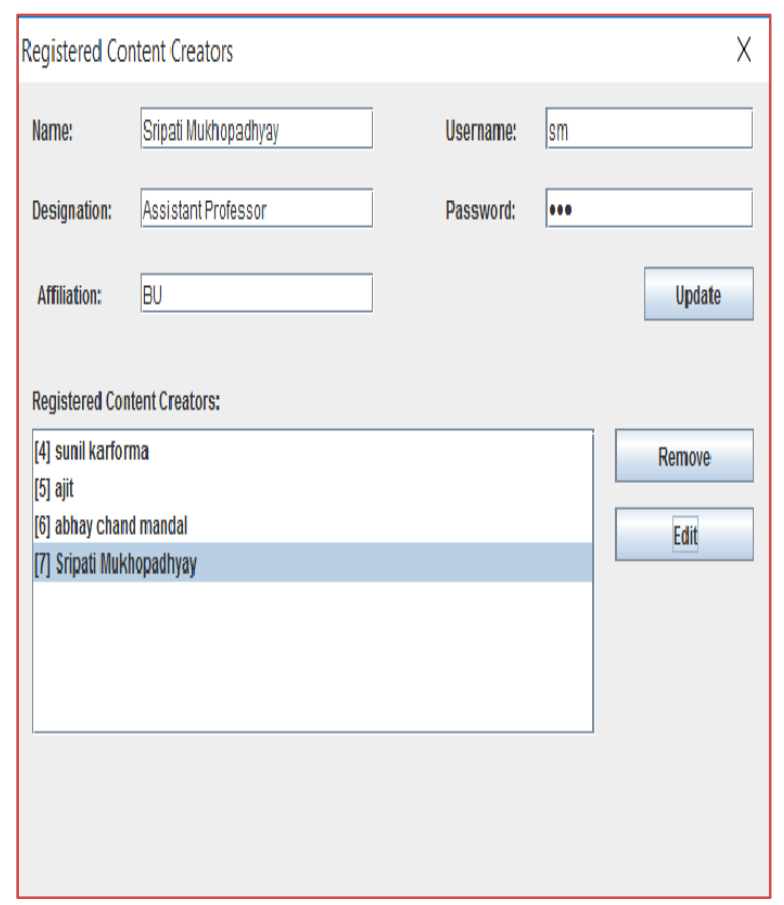

Fig. 6. Content Creator Registration.

After successful enrollment of Learners and registration of Content Creator each content creator prepares tutorials (see Fig. 7) on different topic of different courses and semester.

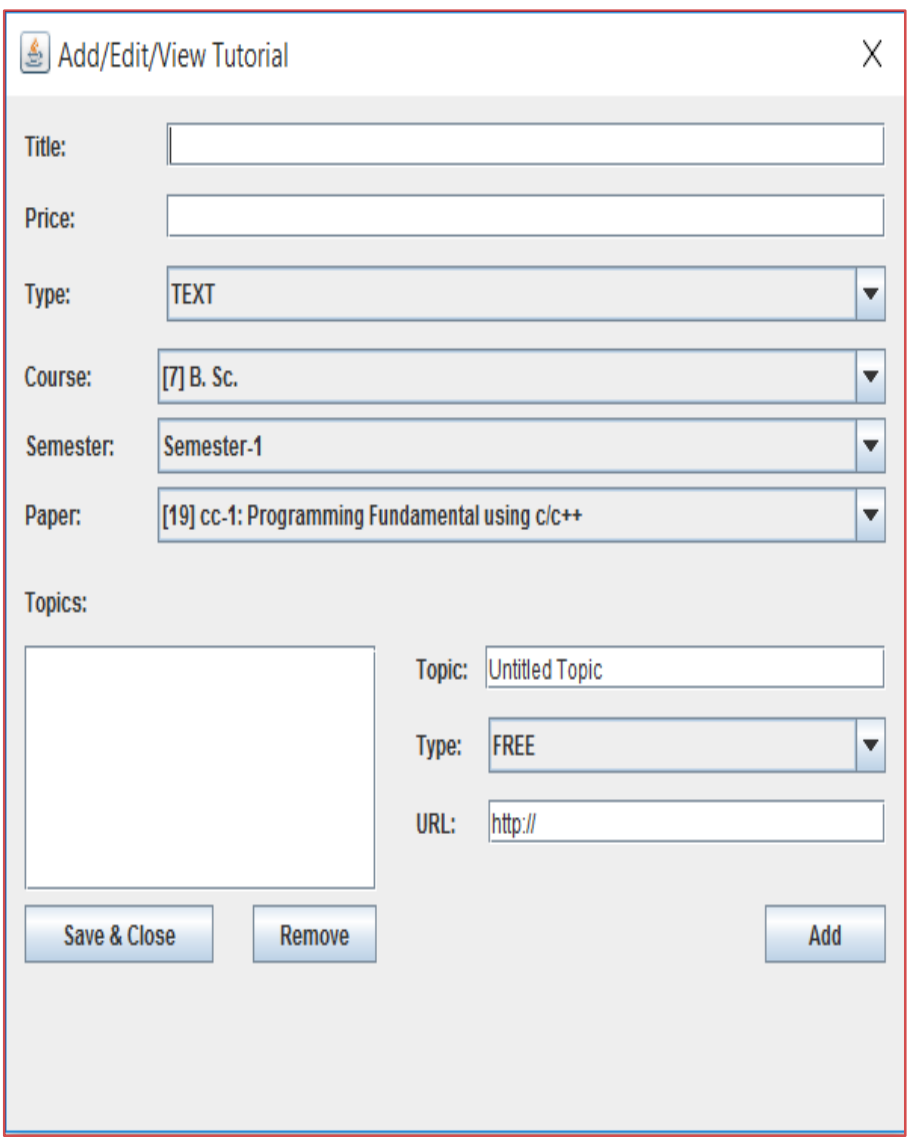

Fig. 7. Tutorial Management. 
When tutorials are managed by different content creators then content creators' create their agent by using JADE environment and for authentication process, they provide valid user id and password. Now Learners have created their own agents by providing authentic user id and password to JADE environment. After entering into the system search tutorial GUI helps Learners to search tutorial (Fig. 8)

\begin{tabular}{|c|c|c|c|c|c|c|c|c|}
\hline \multicolumn{5}{|c|}{ Search Tutorials } & \multicolumn{2}{|c|}{-} & $\square$ & $x$ \\
\hline Course!' & \multicolumn{4}{|c|}{ [7]B.SC. } & & & & v \\
\hline Semester: & \multicolumn{4}{|c|}{ Semester-1 } & & & & v \\
\hline Paper: & \multicolumn{4}{|c|}{ [19] cc-1: Programming Fundamental using cct+ } & & & & $\mathbf{v}$ \\
\hline \multicolumn{2}{|c|}{ My Subscriptions } & \multicolumn{2}{|c|}{ My Account } & & \multicolumn{2}{|c|}{ Subscribe } & \multicolumn{2}{|l|}{ Search } \\
\hline TID & & Author & Tutorial Name & Price & Type & & \#oftopics & \\
\hline 7 & \multicolumn{4}{|c|}{ 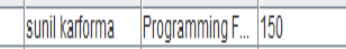 } & TEXT & 0 & & $\Delta$ \\
\hline 8 & \multicolumn{4}{|c|}{ abhay chand ma... programmingifiu... 500} & TEXT & 0 & & \\
\hline 9 & \multicolumn{4}{|c|}{ Sripati Mukhopa... Programming F... 0} & TEXT & 0 & & \\
\hline 10 & \multicolumn{4}{|c|}{ Siripail Mukhopa.... Proggramming F $\mathrm{F}_{\text {... }} 0$} & TEXT & 0 & & \\
\hline 11 & \multicolumn{4}{|c|}{ Sipazal Wukhopa... Programming F... 0} & TEXT & 0 & & \\
\hline 12 & \multicolumn{4}{|c|}{ Sipatil Wukhopa... Propgramming F... 0} & TEXT & 0 & & \\
\hline 13 & \multicolumn{4}{|c|}{ Sripati Mukhopa... Programming F... 0} & TEXT & 0 & & \\
\hline 14 & \multicolumn{4}{|c|}{ Sripail Mukhopa... Programming F... 0} & TEXT & 0 & & \\
\hline 15 & \multicolumn{4}{|c|}{ Sripati Mukhopa... Programming F... 0} & TEXT & 0 & & \\
\hline 18 & \multicolumn{4}{|c|}{ Sipati Mukhopa... Programming F... 0} & TEXT & 0 & & \\
\hline 17 & \multicolumn{4}{|c|}{ Sripati Mukhopa... Programming F... 0} & TEXT & 0 & & \\
\hline 18 & \multicolumn{4}{|c|}{ Sripati Mukhopa... Programming F... 0} & TEXT & 0 & & \\
\hline 19 & \multicolumn{4}{|c|}{ Sripati Mukhopa... Programming F... 0} & TEXT & 0 & & \\
\hline 20 & \multicolumn{4}{|c|}{ Sripati Mukhopa... Programming F... 0} & TEXT & 0 & & \\
\hline 7 & \multicolumn{2}{|c|}{ sunil Kariorma } & $\begin{array}{lll}\text { Programming F... } 150 & 150\end{array}$ & & TEXT & 0 & & \\
\hline 8 & \multicolumn{4}{|c|}{ abhay chand ma... proggramming fu.... 500} & TEXT & 0 & & \\
\hline
\end{tabular}

Fig. 8. Search Tutorial

When Learner enters their course, semester and paper for which tutorial is required then DF Agent provides all the details of the CC agents. It is up to the Learners to choose paid or free tutorials. After selecting tutorial if it is free, then learners need to enter DRMCODE (Fig. 9(a) \& (b)) and for paid tutorial License Key is required for authentication process then only tutorials are accessed by Learners according to their rights. But if DRMCODE and License key are not matched which means Learner is not authorized to access tutorial then access denied message is displayed.

The most exciting property of Agent is their ability to communicate with each other. Agents are communicated with different agents by sending and receiving messages. These things can be easily expressed by JADE's built-in sniffer. This sniffer is a tool that receives messages from all agents in the system, reasons for the information, and presents it from different points of view. The tool is able to visualize messages as a low-level UML sequence diagram and provides a high- level view via dynamically created traceable workflow diagrams. The sniffer view of our DRMSDE system is shown in Fig. 10.

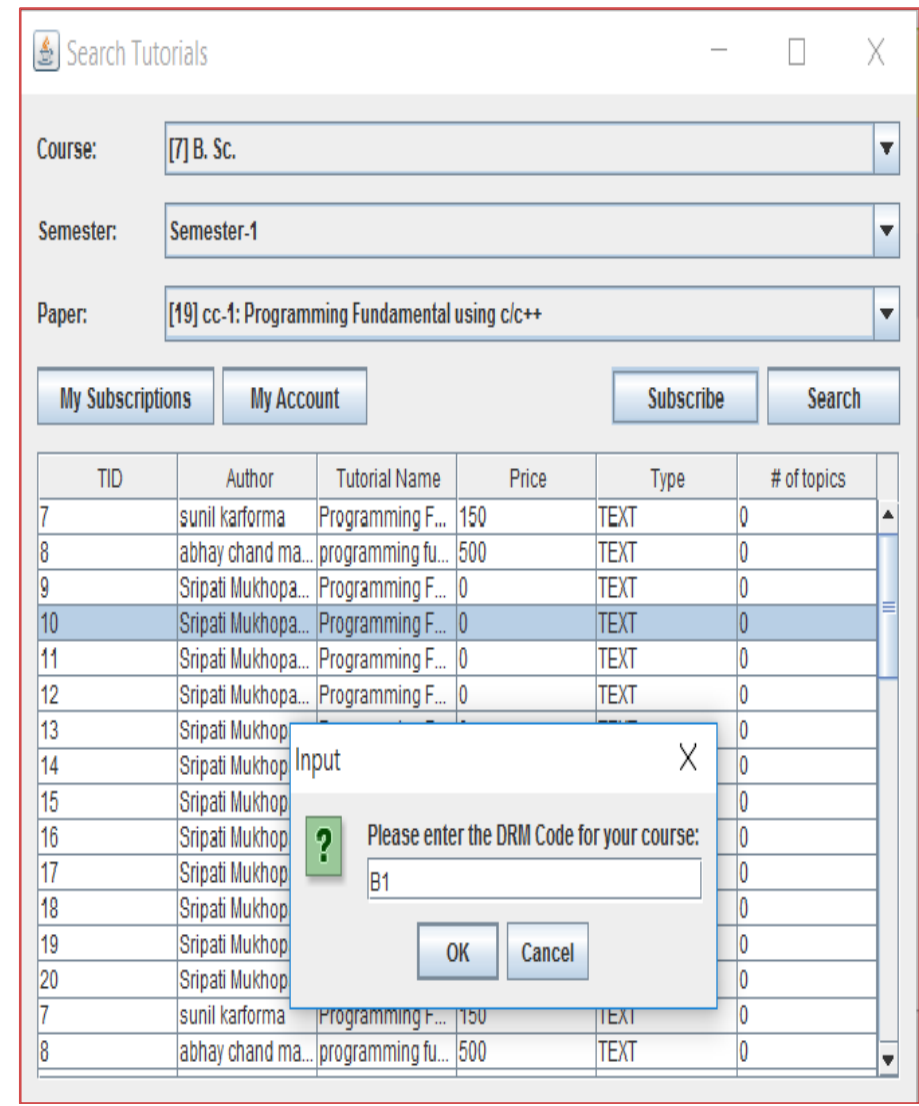

(a)

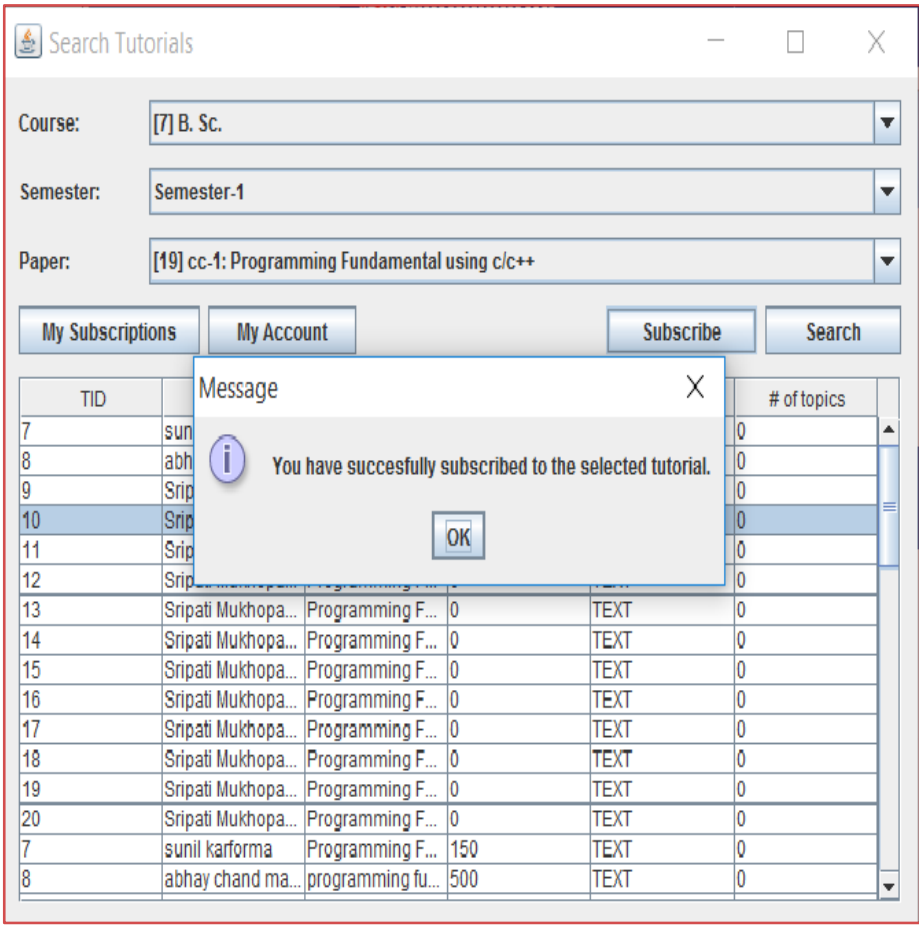

(b)

Fig. 9. Authentication using DRMCODE. 


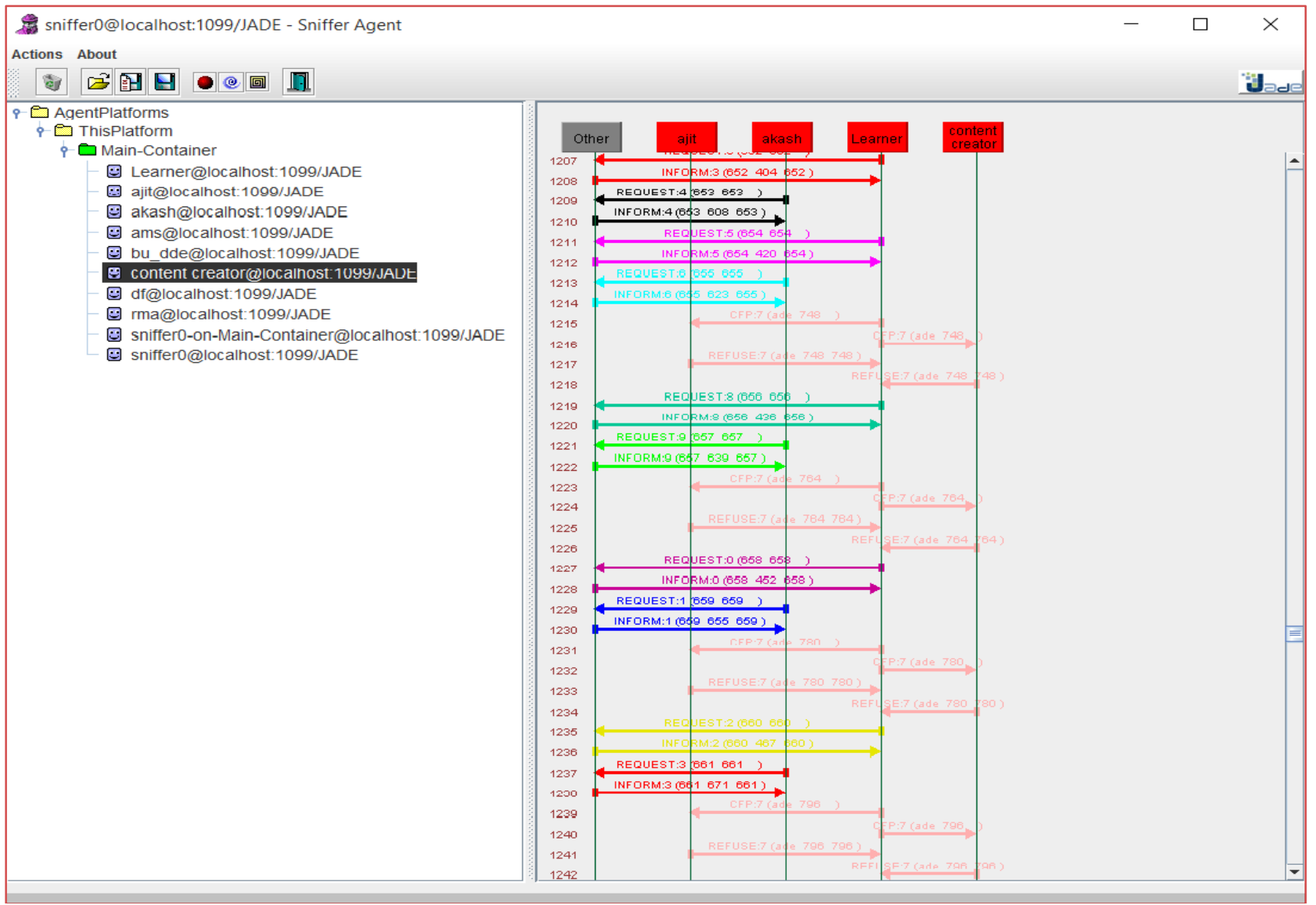

Fig. 10. Sniffer Agent.

\section{B. System Classes}

In our system we have implemented ContentCreatorAgent , LearnerAgent and UniversityAgent classes for creating ContentCreator, Learner and Administrative Manager Agent respectively with the help of JADE built in AMS agent . Agent communications are also initiated by AMS. Agents need interface to perform some action through actionPerformed (...) methods. ContentCreatorGUI, LearnerGUI and UniversityGUI classes are used for ContentCreator, Learner and Administrative Manager Agent respectively. TutorialRequestPerformer class implements a ticker behavior which executes the Learner request on every tick. TutorialRequestServer class catches all incoming requests from Learner agents and replies to them accordingly and DBHelperclass interacting with database. Fig. 11 shows all the classes of our system.

\section{System Database Model}

We are using MYSQL database to fulfill our database requirements. The records of different users, tutorials as well as rights of different users are very efficiently managed by MYSQL. The snapshot of different tables and their interactions are shown in Fig. 12.

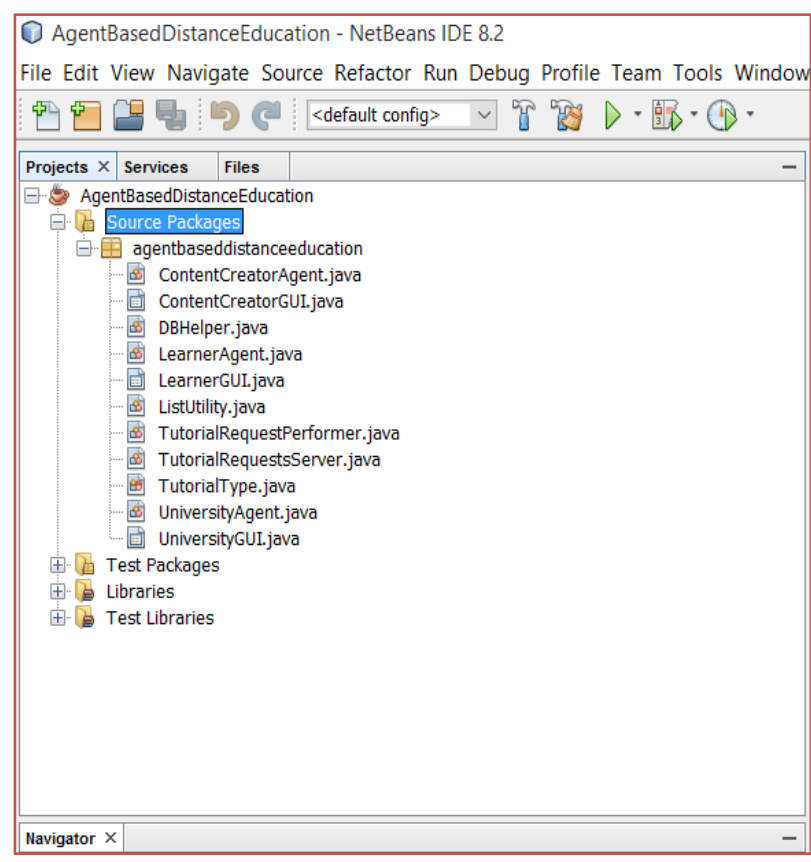

Fig. 11. System Classes. 


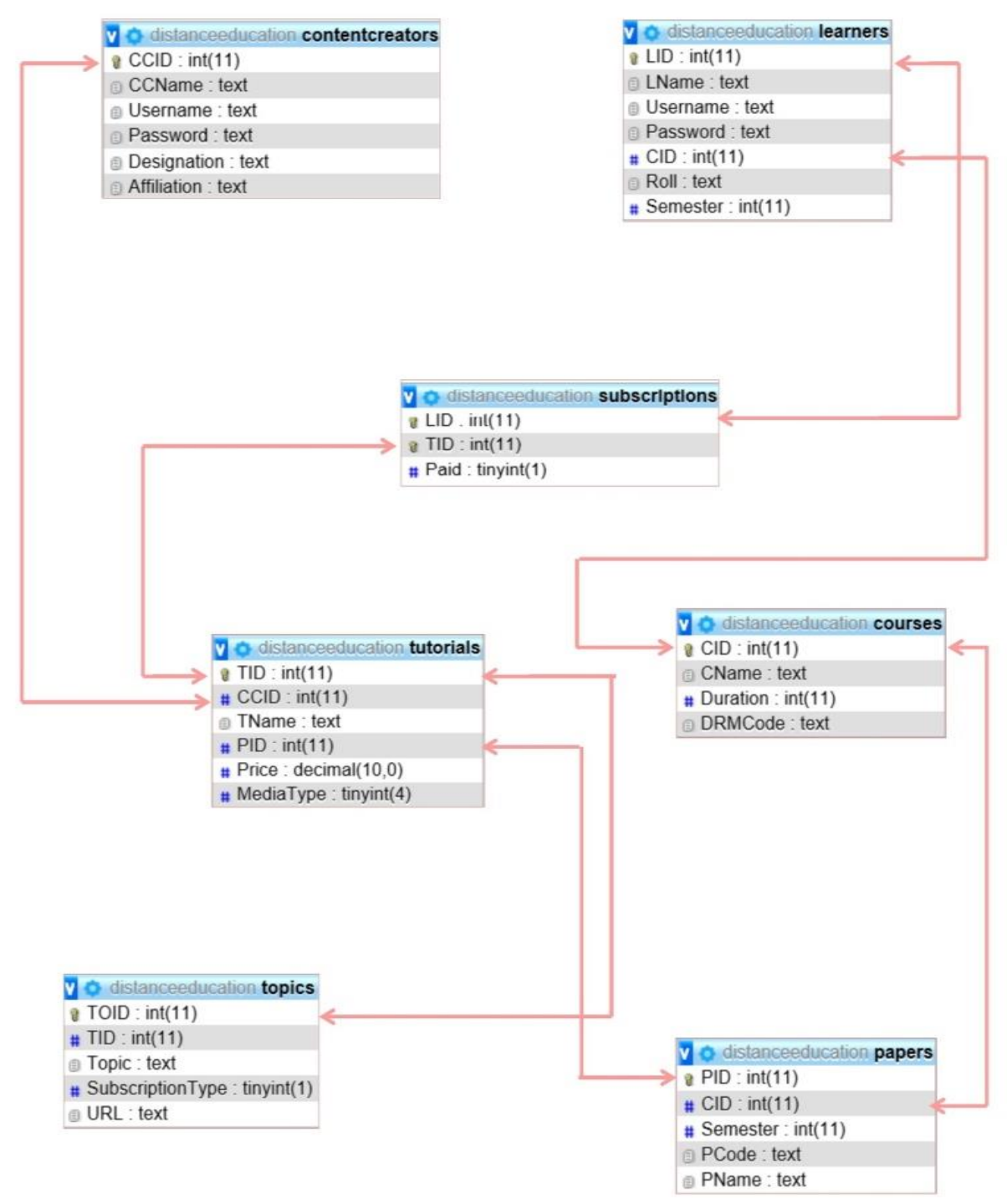

Fig. 12. DRMSDE Database.

\section{LIMITATIONS OF DRMSDE}

Though our system is doing well with DE domain we have noted a few limitations of our study. In this section we are highlighting them:

- Our system allows only three types of users.

- If an unauthorized user tries to enter into the system then such entries are not noticed by the Administrative Manager.

- After the authentication and authorization process if a user download tutorial then our system has no control on that tutorial.

\section{SYSTEMS COMPARISONS}

Now we compare DRMSDE with some of the existing MAS based education system and the results are represented by Table I.
From Table I, it is clear that except ABITS and BOKHARI-IMBLS other intelligent systems are not considered rights management into their systems. In ABITS, DRM is used partially were as in BOKHARI-IMBLS security agent is used for DRM. Our system has also authentication agent for DRM. Now we compare our system with BOKHARI-IMBLS, see Table II.

We think rights management is an important issue for the quality of DE and we focused fully on DRM in it that manages rights of the different user of the system.

Our goal is to protect DC from an unauthorized user and monitor the activity of authorized user so that learner cannot misuse the DC and use according to their rights. Whenever a learner is completed it course its accesses rights have become invalid. 
TABLE I. SYSTEMS COMPARISONS

\begin{tabular}{|c|c|c|c|c|c|}
\hline NAME OF SYSTEM & $\begin{array}{l}\text { PURPOSE OF } \\
\text { DEVELOPMENT }\end{array}$ & $\begin{array}{l}\text { PROPOSED BY / } \\
\text { DEVELOPED B Y }\end{array}$ & $\begin{array}{l}\text { TECHNOLOGICAL } \\
\text { TOOLS }\end{array}$ & NAME OF AGENTS & DRM \\
\hline ELECTROTUTOR [18] & $\begin{array}{l}\text { MULTI-AGENT BASED E- } \\
\text { LEARNING SYSTEM FOR } \\
\text { DISTANCE LEARNING } \\
\text { ENVIRONMENT }\end{array}$ & $\begin{array}{l}\text { DISTRIBUTED } \\
\text { INTELLIGENT } \\
\text { LEARNING } \\
\text { ENVIRONMENT }\end{array}$ & JADE, KQML & $\begin{array}{l}\text { PEDAGOGICAL, } \\
\text { COMMUNICATION, } \\
\text { STUDENT MODEL, } \\
\text { REMOTE }\end{array}$ & NO \\
\hline $\begin{array}{l}\text { AGENT BASED } \\
\text { INTELLIGENT } \\
\text { TUTORING } \\
\text { SYSTEM(ABITS) [19] }\end{array}$ & $\begin{array}{l}\text { ADOPTIVE WEB-BASED } \\
\text { TUTORING SYSTEM }\end{array}$ & $\begin{array}{l}\text { NICOLA CAPUANO, } \\
\text { MARCO MARSELLA } \\
\text {, SAVERIO } \\
\text { SALERNO }\end{array}$ & $\begin{array}{l}\text { HTML, VRML, CLASS, } \\
\text { XML/RDF [10] }\end{array}$ & $\begin{array}{l}\text { EVALUATION, AFFECTING } \\
\text { AND PEDAGOGICAL }\end{array}$ & $\begin{array}{l}\text { PARTIALLY NO } \\
\text { AGENT FOR } \\
\text { DRM }\end{array}$ \\
\hline BAGHERA[20] & $\begin{array}{l}\text { A WEB BASED } \\
\text { ENVIRONMENT FOR } \\
\text { TEACHING GEOMETRY } \\
\text { PROOF }\end{array}$ & $\begin{array}{l}\text { CARINE WEBBER, } \\
\text { LORIS BERGIA, } \\
\text { SYLVIE PESTY AND } \\
\text { NICOLAS } \\
\text { BALACHEFF }\end{array}$ & JATLITE, FIPA-ACL & $\begin{array}{l}\text { STUDENT'S PERSONAL } \\
\text { INTERFACE, TUTOR, } \\
\text { MEDIATOR, TEACHER'S } \\
\text { PERSONAL INTERFACE } \\
\text {,ASSISTANT }\end{array}$ & NO \\
\hline MAS-PLANG[21] & $\begin{array}{l}\text { TEACHING SUPPORT } \\
\text { UNIT }\end{array}$ & $\begin{array}{l}\text { CLARA-INÉS PEÑA, } \\
\text { JOSE-L MARZO, } \\
\text { JOSEP-LLUIS DE LA } \\
\text { ROSA }\end{array}$ & $\begin{array}{l}\text { JADE,JAVA SCRIPT, } \\
\text { XML, RMI, CGI, FLASH }\end{array}$ & $\begin{array}{l}\text { SONIA, SYNTHETIC, USER , } \\
\text { DIDACTIC , SUPERVISOR , } \\
\text { PEDAGOGIC, } \\
\text { CONTROLLER, EXERCISE } \\
\text { ADAPTER }\end{array}$ & NO \\
\hline $\begin{array}{l}\text { EMOTIONAL MULTI- } \\
\text { AGENTS SYSTEM } \\
\text { FOR PEER TO PEER } \\
\text { E-LEARNING } \\
\text { (EMASPEL) }[22]\end{array}$ & $\begin{array}{l}\text { COLLECTIVE AND } \\
\text { COLLABORATING E- } \\
\text { LEARNING SYSTEM ON } \\
\text { THE PEER TO PEER } \\
\text { NETWORK }\end{array}$ & $\begin{array}{l}\text { MOHAMED BEN } \\
\text { AMMAR , } \\
\text { MAHMOUD NEJI , } \\
\text { ADEL.M ALIMI }\end{array}$ & MADKIT , JXTA & $\begin{array}{l}\text { INTERFACE, } \\
\text { EMOTIONAL,CURRICULUM } \\
\text {, TUTOR, THE EMOTIONAL } \\
\text { EMBODIED } \\
\text { CONVERSATIONAL }\end{array}$ & NO \\
\hline $\begin{array}{l}\text { AGENT-BASED } \\
\text { APPROACH TO } \\
\text { DYNAMIC ADAPTIVE } \\
\text { LEARNING (ABDAL) }\end{array}$ & $\begin{array}{l}\text { WORKS FOR DISTANCE } \\
\text { EDUCATION } \\
\text { ENVIRONMENT }\end{array}$ & $\begin{array}{l}\text { SHANGHUA SUN, } \\
\text { MIKE JOY, AND } \\
\text { NATHAN } \\
\text { GRIFFITHS }\end{array}$ & APPLETS [23] & $\begin{array}{l}\text { PREFERENCE , } \\
\text { ACCOUNTING , EXERCISE, } \\
\text { TEST }\end{array}$ & NO \\
\hline ALLEGRO [24] & $\begin{array}{l}\text { TO SUPPORT TEACHING } \\
\text { LEARNING PROCESS }\end{array}$ & $\begin{array}{l}\text { ROSA M. VICCARI, } \\
\text { DEMETRIO A. } \\
\text { OVALLE, JOVANI A. } \\
\text { JIM'ENEZ }\end{array}$ & $\begin{array}{l}\text { CASE BASED } \\
\text { REASONING, } \\
\text { LEARNING OBJECT, } \\
\text { COLLABORATIVE } \\
\text { FEATURE }\end{array}$ & $\begin{array}{l}\text { TUTOR , STUDENT, } \\
\text { INTERFACE, EXPERT, } \\
\text { DIAGNOSIS, } \\
\text { COLLABORATIVE }\end{array}$ & NO \\
\hline $\begin{array}{l}\text { BOKHARI } \\
\text { INTELLIGENT } \\
\text { MULTI-AGENT } \\
\text { BASED E-LEARNING } \\
\text { SYSTEM (BOKHARI- } \\
\text { IMBLS) [9] }\end{array}$ & $\begin{array}{l}\text { WEB-BASED } \\
\text { INTERACTIVE E- } \\
\text { LEARNING SYSTEM } \\
\text { DESIGNED FOR THE } \\
\text { DISTANCE LEARNING } \\
\text { ENVIRONMENT }\end{array}$ & $\begin{array}{l}\text { MOHAMMAD } \\
\text { UBAIDULLAH } \\
\text { BOKHARI AND } \\
\text { SADAF AHMAD }\end{array}$ & $\begin{array}{l}\text { PROMETHEUS } \\
\text { METHODOLOGY }\end{array}$ & $\begin{array}{l}\text { STUDENT INTERFACE } \\
\text { AGENT, TUTOR } \\
\text { INTERFACE AGENT, } \\
\text { COLLABORATION AGENT, } \\
\text { INTELLIGENT DECISION } \\
\text { SUPPORT AGENT, } \\
\text { TEST/EVALUATION AGENT } \\
\text {, LESSON PLANNING } \\
\text { AGENT AND SECURITY } \\
\text { AGENT }\end{array}$ & YES \\
\hline
\end{tabular}

TABLE II. BOKHARI-IMBLS vs. DRMSDE

\begin{tabular}{|l|l|l|}
\hline & BOKHARI-IMBLS & DRMSDE \\
\hline No of User & This System allow two users & DRMSDE allow three user \\
\hline Right Management of Users & Not Consider & Rights Management is key to our system \\
\hline Encryption of DC & $\begin{array}{l}\text { Advanced Encryption Standard, or AES, is } \\
\text { used to encrypt database }\end{array}$ & Development of encryption technique for DC is under process. \\
\hline Security & Achieved by login id and password & $\begin{array}{l}\text { DRMSDE has two level of security } \\
\text { Authentication is done by user id and password } \\
\text { Authorization is done by DRM code }\end{array}$ \\
\hline
\end{tabular}




\section{CONCLUSION}

DE and DRM are two popular domains of research. In this paper, we used both of them and implement a Multi-agent based model called DRMSDE using JADE. Our main objective is to protect DC from unauthorized users and also promote fair use of DC among authorized user. For DRM here we use Authentication and Authorization model that is widely accepted in the domain of education. Different users of the system are guided by intelligent Agents at each level so that we protect our system from unauthorized access efficiently. Agents interact with the database to verify the users' authenticity and authorization. After successful verification agents allow users to access the database. Though rights of the user may depend on institutional policy and our system is ready to easily accommodate those changes by modifying Agents or introducing new Agents if required. Our purpose is to increase security, quality, trust, and accessibility of DE with intelligent agents. The rights of users are solely maintained in our system. In future to enhance the quality of DRMSDE we will design some agents in our system that constantly monitors our system and inform the administrative manager if some unauthorized users are trying to access our DC, and for protection of DC we will develop a suitable encryption and decryption technique.

\section{ACKNOWLEDGMENT}

I acknowledge Prof Ahmet ŞANSLI for answering my questions related with his system EDU-DRM and allow me to access his paper "EDU-DRM: A digital rights management (DRM) system for K-12 education" which in press.

\section{REFERENCES}

[1] A. Ozmen , A. Şansli , V. H.Şahin"EDU-DRM: A digital rights management (DRM) system for K-12 education" Scientialranica, in press.

[2] N. Mclean, R. Iannella, "Digital rights management (DRM) in education - the need for standardization", Australian IMS Centre;2002

[3] A K Singh, S Karforma, S Mukhopadhyay," Intelligent digital rights management system for distance education (DRMSDE) using multiagent system", International Journal of Mechanical Engineering and Technology (IJMET) Vol. 9, Issue 10, pp. 429-437,October 2018.

[4] J. Xie , C. C. Liu, "Multi-agent systems and their applications", Journal of International Council on Electrical Engineering. Vol. 7 , Issue 1, pp 188-197, 2017.

[5] T. Manev , S. Filiposka, "Semantic aware multi-agent system advantages", International Journal of Informatics and Communication Technology (IJ-ICT), Vol. 3 , Issue 1, pp1-12,2014.

[6] F Bellifemine, F. Bergenti, G. Caire, A. Poggi , "JADE- A JAVA agent development frame work", Springer, Multiagent Programming, Vol. 15, pp. 125-147,2005.

[7] A K Singh, S Karforma, S Mukhopadhyay, "A survey on digital rights management in distance education", 1st International Conference on Innovations in Computer Science (ICICS-2018), India, 21st and 22nd December 2018,

[8] Collier , R Robson ,'Digital Rights Management for Research and Education", Article, December 2,2004.

[9] M. U. Bokhari, S. Ahmad, “BOKHARI- Intelligent Multi-agent based e-Learning System (IMBLS) for Interactive Distance Learning”,
Advances in Computer Science and Information Technology (ACSIT), Vol 1, No 1, pp. 21-26 October, 2014

[10] M. Martin , G. Agnew , D. L. Kuhlman , J. H. McNair , W. R. Rhodes , R. Tipton, "Federated Digital Rights Management", D-Lib Magazine, Vol. 7 , Number 6, july/august 2002

[11] R. McGreal, T. Anderson, G. Babin, S. Downes, N. Friesen, K. Harrigan, M. Hatala, D. MacLeod, M. Mattson, , G. Paquette, G. Richards, , T. Roberts, \& S. Schafer, "EduSource: Canada's learning object repository network", International Journal of Instructional Technology and Distance Learning, Vol. 1,Issue3, March 2004.

[12] J. Dalziel, "Reflections on the COLIS (Collaborative Online Learning and Information Systems) demonstrator project and the "learning object lifecycle"', Winds of Change in the Sea of Learning: Proceedings of the 19th Annual Conference of the Australasian Society for Computers in Learning in Tertiary Education, Auckland, New Zealand , pp. 159-166, 2002.

[13] F.Bellifemine, G.Caire, D Greenwood," Developingmulti-agent systemswith JADE", John Wiley \& Sons Ltd, 2007.

[14] V. Sandita, C. I. Popirlana, "Developing a multi - agent system in Jade for information management in educational competence domains", 2nd Global Conference on Business, Economics, Management and Tourism , Science Direct ,pp. 478-486, Prague, 2014.

[15] J. Su , C. Y. Wu, "JADE Implemented mobile multi-agent based , distributed information platform for pervasive health care monitoring", Elsevier Applied Soft Computing, Vol. 11, Issue 1, pp 315-325, 2011.

[16] A. Gupta , D. K Srivastava , S. Jain, "Auction System for automated Ecommerce : Jade based multi-agent application", International Journal of Engineering and Computer Science, Vol. 5, Issue-09 , pp 18019$18024,2016$.

[17] Y.Etene, P.Owoche, R. Oboko “ A multi-agent system to support ICT based distance learning through modeling of learner needs : the case of bahelar of education at the University of Nairobi", IOSR Journal of Computer Engineering, Vol. 18, Issue-5 , pp 26-31,2016.

[18] Ricardo Azambuja Silveira, Rosa Maria Vicari , Developing Distributed Intelligent Learning Environment with JADE - Java Agents for Distance Education Framework, Proceedings of the 6th International Conference on Intelligent Tutoring Systems, Biarritz, France and San Sebastian, Spain, 2002, 105-118

[19] S. Ahmad, Literature Review, Designing Multiagent Intelligent System for Interactive e-Learning, PhD Thesis. Aligarh Muslim University, India ,2014.

[20] C Webber, L Bergia, S Pesty and N Balacheff, Baghera project: a multiagent architecture for human learning, Proceedings of the Workshop Multi-Agent Architectures for Distributed Learning Environments, AIED2001, San Antonio, TX, USA, pp-12-17,2001

[21] Clara-Inés Peña, Jose-L Marzo, Josep-Lluis de la Rosa, Intelligent Agents in a Teaching and Learning Environment on the Web, Proceedings of the 2nd IEEE International Conference on Advanced Learning Technologies, ICALT2002, Kazan, Russia ,pp- 21-27, 2002.

[22] M. B. Ammar, M. Neji , A. M. Alimi , Emotional multi-agents system for peer to peer elearning (EMASPEL), DIWEB'06 Proceedings of the 5 th WSEAS International Conference on Distance Learning and Web Engineering, Corfu Island, Greece, pp- 164-170 ,2005.

[23] S. Sun, M. Joy, N. Griffiths, An agent-based approach to dynamic adaptive learning, in Agent Based Systems for Human Learning (ABSHL) Workshop, the 4th International Joint Conference on Autonomous Agents and Multi Agent Systems (AAMAS), Utrecht, Netherlands, pp-48-58, 2005.

[24] R. M. Viccari, D. A. Ovalle, J. A. Jim’́enez, ALlEGRO: Teaching/Learning Multi-Agent Environment using Instructional Planning and Cases- Based Reasoning (CBR), in Centro Latinoamericano de EstudiosenInformática (CLEI) Electronic Journal, vol 10 , issue 1, paper 4, 2007. 